\title{
Understanding benefits and addressing misperceptions and barriers to intrauterine device access among populations in the United States
}

This article was published in the following Dove Press journal:

Patient Preference and Adherence

3 July 2014

Number of times this article has been viewed

\section{Jennie Yoost}

Marshall University Department of Obstetrics and Gynecology, Huntington, WV, USA
Correspondence: Jennie Yoost Marshall University Department of Obstetrics and Gynecology, 1600 Medical Center Drive Suite 4500, Huntington, WV 2570I, USA

$\mathrm{Tel}+|30469| \quad \mid 460$

Fax + I 304 69| |453

Email yoost@marshall.edu
Abstract: Three intrauterine devices (IUDs), one copper and two containing the progestin levonorgestrel, are available for use in the United States. IUDs offer higher rates of contraceptive efficacy than nonlong-acting methods, and several studies have demonstrated higher satisfaction rates and continuation rates of any birth control method. This efficacy is not affected by age or parity. The safety of IUDs is well studied, and the risks of pelvic inflammatory disease, perforation, expulsion, and ectopic pregnancy are all of very low incidence. Noncontraceptive benefits include decreased menstrual blood loss, improved dysmenorrhea, improved pelvic pain associated with endometriosis, and protection of the endometrium from hyperplasia. The use of IUDs is accepted in patients with multiple medical problems who may have contraindications to other birth control methods. Yet despite well-published data, concerns and misperceptions still persist, especially among younger populations and nulliparous women. Medical governing bodies advocate for use of IUDs in these populations, as safety and efficacy is unchanged, and IUDs have been shown to decrease unintended pregnancies. Dispersion of accurate information among patients and practitioners is needed to further increase the acceptability and use of IUDs.

Keywords: IUD, contraception, levonorgestrel, copper

\section{Background}

The evolution of the intrauterine device (IUD) has led to a safe and effective contraceptive choice for many women. The efficacy in pregnancy prevention far surpasses other daily and scheduled methods such as pills, patches, and contraceptive rings. Satisfaction rates rank high among IUD users in the United States (US) compared to other methods, and complication rates have been shown to be low. The IUD has also emerged as a first-line recommendation for women with heavy bleeding, pelvic pain, and need for menstrual suppression. Yet despite this favorable profile, only $5.5 \%$ of women in the US use IUDs. ${ }^{1}$ Contributing to this low use are the many myths and exaggerated complications that are perpetuated through the media and by practitioners. Lack of knowledge by patients and practitioners regarding noncontraceptive benefits, appropriate candidates for IUDs, and provision of services compounds this problem. The barriers to IUD use need to be addressed so that there is a better understanding of their safety, efficacy, and utility, granting more women access to this beneficial contraceptive choice.

There are three IUDs available for use in the US. Two contain the progestin levonorgestrel (Mirena ${ }^{\circledR}$ and Skyla ${ }^{\circledR}$, Bayer AG, Leverkusen, Germany). The other is the copper IUD (Paragard ${ }^{\circledR}$, Teva Pharmaceuticals USA, Sellersville, PA, USA). The copper IUD was developed in 1984 and is a T-shaped device of polyethylene wrapped in a copper wire measuring $36 \mathrm{~mm}$ long by $32 \mathrm{~mm}$ wide 


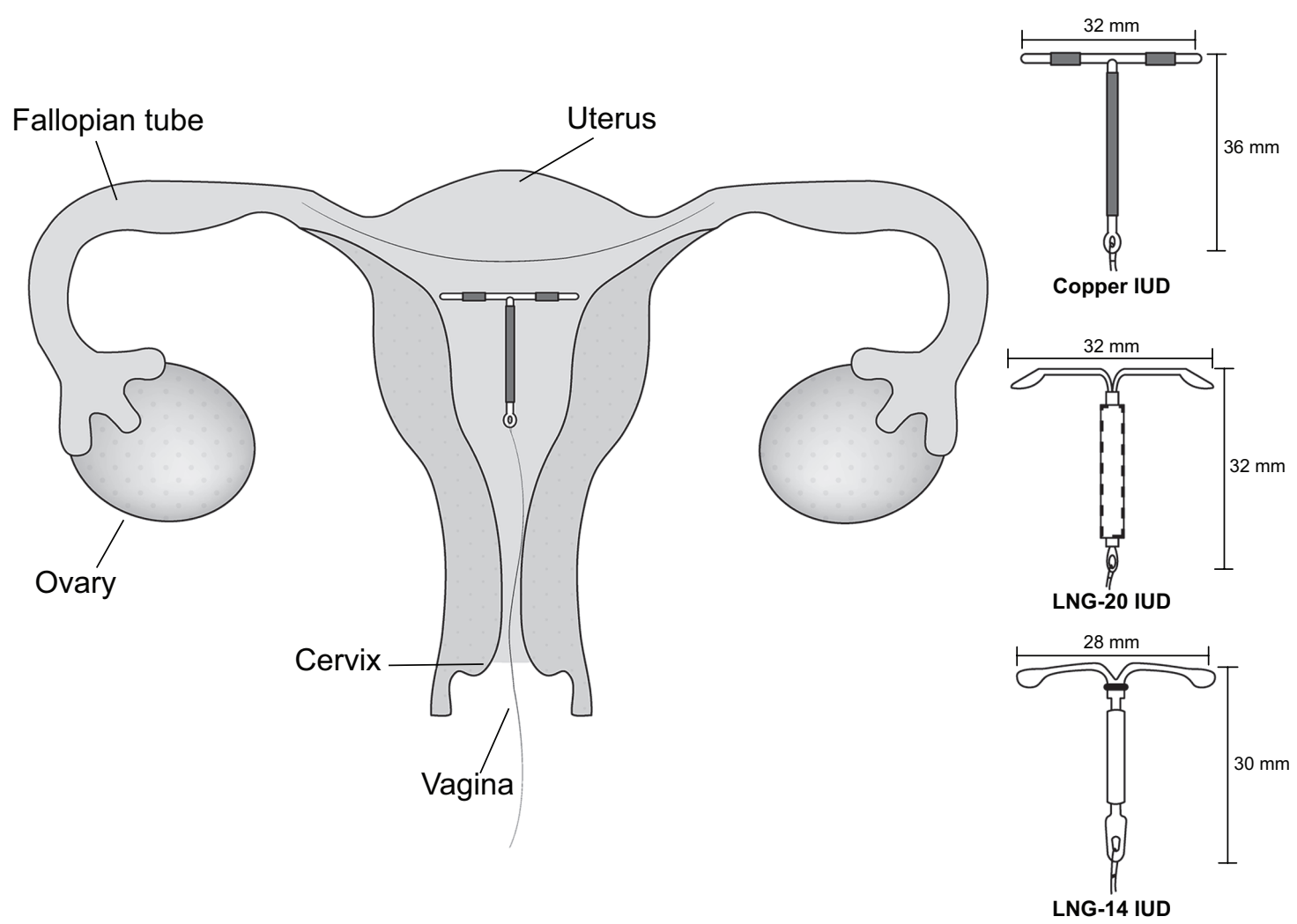

Figure I Dimensions and placement of intrauterine devices.

Note: Figure courtesy of Matt Crutchfield, Marshall University School of Medicine, Department of Graphic Design, with permission from the Joan C. Edwards School of Medicine.

Abbreviation: IUD, intrauterine device.

(Figure 1). It is US Food and Drug Administration (FDA) approved for 10 years of use. ${ }^{2}$ Prefertilization effects of the copper ions include inhibition of sperm motility, viability, inhibition of capacitation, destruction of the ovum, and induction of a sterile inflammatory response in the endometrium. ${ }^{3}$ Postfertilization effects such as damage to the fertilized ovum prior to implantation may occur as well, but most evidence suggests that prefertilization effects constitute the primary mechanism of action. ${ }^{2,4}$

The progestin IUDs come in two different sizes, both containing the progestin levonorgestrel (LNG). Mirena ${ }^{\circledR}$, developed in 2000, is FDA approved for 5 years and contains $52 \mathrm{mg} \mathrm{LNG}$, which is released at $20 \mu \mathrm{g}$ daily. ${ }^{5}$ It is hereafter referred to as the LNG-20 IUD. Skyla ${ }^{\circledR}$ was most recently FDA approved in 2013, contains $13.5 \mathrm{mg} \mathrm{LNG}$, and is effective for 3 years of use, releasing $14 \mu \mathrm{g}$ per day. It is hereafter referred to as the LNG-14 IUD. The LNG-14 IUD is slightly smaller in size, measuring $30 \mathrm{~mm}$ long by $28 \mathrm{~mm}$ wide, compared to the dimensions of the LNG-20 IUD of $32 \mathrm{~mm}$ by $32 \mathrm{~mm}$ (Figure 1). ${ }^{6}$ To prevent pregnancy, LNG causes suppression of the endometrium, increased amount and viscosity of cervical mucus, and decreases tubal motility.
Pre- and postfertilization effects occur before implantation. ${ }^{2}$ Up to $58 \%-63 \%$ of women may continue to ovulate with LNG IUDs, yet will have decreased menstrual bleeding due to the progestin effect on the endometrium. ${ }^{7}$

All IUDs are placed through the cervix into the uterine cavity by a trained provider. This procedure is most commonly done in the office, but in special circumstances such as in the case of mentally limited patients and younger adolescents, it can be done under sedation. Menstrual-like cramping is typical for patients to experience during insertion and for the first few days after placement. Nulliparous women in most studies have higher rates of discomfort with placement compared to multiparous patients, ${ }^{8}$ yet are appropriate candidates for use. ${ }^{9}$ The use of analgesics such as topical lidocaine, injectable lidocaine, and cervical ripening agents such as misoprostol has been studied without evidence supporting their use for decreased discomfort with insertion. ${ }^{10}$

Insertion of IUDs has typically been done during menses, but insertion can be performed at any point in the menstrual cycle as long as the practitioner reasonably excludes pregnancy. ${ }^{2}$ Backup contraception is not needed after copper IUD insertion, but is needed for 7 days after insertion of 
the LNG IUDs. The exception to this is if the LNG IUD is placed within 5 days of menstrual initiation, or immediately after childbirth, abortion, or switching from an alternative contraceptive method. ${ }^{2,6}$ Placement is confirmed by a speculum exam performed 2-4 weeks after insertion to visualize the strings protruding from the cervical os. Alternatively, in younger patients or those with mental disability, a pelvic ultrasound can be used to confirm proper placement in the uterine cavity.

\section{Efficacy}

Nearly half of the 6.7 million pregnancies reported in the US each year are unintended, and this rate is even higher among 15 - to 19 -year-old women (82\%). ${ }^{11}$ The contraceptive efficacy of IUDs has been illustrated in many studies. The copper IUD has a reported failure rate at 1 year of $0.8 \%$, and a 10-year failure rate comparable to female sterilization of 1.9 per $100 .{ }^{12}$ A Cochrane Review evaluating 21 randomized trials concluded that the effectiveness of the LNG-20 IUD is similar to the copper IUD; ${ }^{13}$ other studies have shown the LNG-20 IUD to be among the most effective contraceptive methods, with a failure rate of $0.1 \%$ at 1 year and $0.5 \%$ at 5 years, similar to or better than female sterilization. ${ }^{14}$ Clinical trials of the LNG-14 IUD yielded similar results, showing a cumulative pregnancy rate of $0.9 \%$ over 3 years. ${ }^{15}$

Of great importance is that this efficacy is not altered by or related to patient age. A large landmark study in St Louis, MO, USA grouped the copper IUD, LNG-20 IUD, and another contraceptive method, the subdermal implant, together as long-acting reversible contraceptives (LARCs) and compared them to methods such as the pill, patch, and ring that require patient compliance. Women aged 14-45 years were followed prospectively for 3 years. The failure rate among pill, patch, and ring users was 4.55 per 100 patient-years, compared to only 0.27 per 100 patient-years among IUD and implant users. The risk of unintended pregnancy among LARC users was unaffected by age, whereas the risk for women using pills, patches, or rings was almost twice as high for those younger than 21 years compared with older women. ${ }^{16}$ It is known that adolescents have higher discontinuation rates of hormonal birth control, putting them at risk for unintended pregnancy. ${ }^{17}$ Data from the Pregnancy Risk Assessment Monitoring System indicate that $45.2 \%$ of young women age 15-19 who experience a live birth have used moderate or very effective methods of contraception in the past, suggesting that these adolescents struggled with adherence. ${ }^{18}$ It is for this reason that the American College of Obstetrics and Gynecology recommends the use of
LARC methods such as LNG IUDs and the copper IUD as first-line methods for contraception in this age group. ${ }^{9}$

\section{Safety}

Due to backlash against IUDs, mainly caused by complications from the Dalkon Shield in the $1970 \mathrm{~s},{ }^{2}$ there are many safety misperceptions that persist with modern-day IUDs. This has greatly impacted the perception that IUDs are not appropriate for nulliparous women or adolescents. As stated previously, not only is the IUD appropriate, but it should be considered first-line for contraception in these populations. Reservations about the incidence of pelvic inflammatory disease (PID) in this population are the most common. ${ }^{19,20}$ The risk of PID is no greater with IUD use than in the general population. The only initial increase in risk is seen in the first 20 days after insertion. Combined clinical trial data from the World Health Organization found that the development of PID was 6.3 times greater during the first 20 days after IUD insertion, ${ }^{21}$ which is felt to be due to bacterial contamination from the procedure, and not the IUD specifically. However, after the first 20 days, the risk of infection returns to a baseline of 1.4 per 1,000 women-years throughout 8 years of use. This is the same or lower than the risk of PID in women without IUDs. ${ }^{22-24}$ In the newer LNG-14 IUD, PID was diagnosed in two out of 1,432 women over the 3-year study period of a clinical trial. ${ }^{15}$ There is also an argument that LNG IUD use can be preventative to the development of PID. Given that LNG IUDs work to increase cervical mucus and reduce menstrual blood loss, there is less of a risk of bacterial ascension through the cervix into the upper genital tract, and less risk of retrograde menstruation through the fallopian tubes. ${ }^{5,25}$

The majority of PID infections occur in women under age 25, and women aged 15-24 comprise half of the 18.9 million new cases of sexually transmitted diseases (STDs) in the US each year. ${ }^{26,27}$ Yet despite this proportionally higher risk, same-day insertion of IUDs can be carried out in all patients, including adolescents, with appropriate screening. All adolescents should undergo STD screening prior to or at the time of insertion. Nucleic acid amplification tests are the most sensitive, and can be done on cervical samples or urine specimens. ${ }^{28}$ The risk of PID with IUD placement is $0 \%-5 \%$ when insertion occurs with an undetected infection. ${ }^{29}$ Furthermore, women with positive chlamydia testing after IUD insertion are unlikely to develop PID, even with retention of the IUD, if the infection is treated promptly. ${ }^{30}$ Based on this data, the US medical eligibility criteria, released by the Centers for Disease Control (CDC), rates IUD use in 
Table I Conditions acceptable for IUD use based on category of risk I or 2

\begin{tabular}{|c|c|c|}
\hline \multirow[t]{2}{*}{ Condition } & \multicolumn{2}{|l|}{ Category } \\
\hline & LNG IUD & Copper IUD \\
\hline Past ectopic pregnancy & I & I \\
\hline Smoking & I & I \\
\hline Obesity & I & I \\
\hline Bariatric surgery & I & I \\
\hline Hypertension (systolic 140-159 or diastolic 90-99) & I & I \\
\hline Hypertension (systolic $\geq 160$ or diastolic $\geq 100$ ) & 2 & I \\
\hline History of deep venous thrombosis or pulmonary embolism & 2 & I \\
\hline Acute deep venous thrombosis or pulmonary embolism & 2 & 2 \\
\hline Valvular heart disease & I & I \\
\hline Endometriosis & I & 2 \\
\hline Dysmenorrhea & I & 2 \\
\hline Benign breast disease & I & $\mathrm{I}$ \\
\hline Endometrial hyperplasia & I & I \\
\hline Past pelvic inflammatory disease* & $\mathrm{I} / 2$ & $\mathrm{I} / 2$ \\
\hline Diabetes & 2 & I \\
\hline Inflammatory bowel disease & $\mathrm{I}$ & I \\
\hline Anemia & I & 2 \\
\hline
\end{tabular}

Notes: Category I: A condition for which there is no restriction for the use of contraceptive method. Category 2: A condition for which the advantages of using the method generally outweigh the theoretical or proven risks. *Category I with subsequent pregnancy. Category 2 without subsequent pregnancy.

Modified from US Medical Eligibility Criteria for Contraceptive Use, 20 I0. Centers for Disease Control and Prevention (CDC). MMWR Recomm Rep. 20I0;59(RR-4):I-86. ${ }^{31}$ Abbreviation: IUD, intrauterine device.

adolescents as category 2 (Table 1 ), meaning that the benefits outweigh the risks. ${ }^{31}$ Successful IUD use, even in high-risk populations, is dependent on effective STD screening and follow-up and age-specific counseling. ${ }^{28}$ Same-day insertion also addresses barriers of lack of transportation and waning motivation in a high-risk population.

Contraindications for IUD use are listed in Table 2. Patients should be assessed for signs and symptoms of PID prior to IUD insertion. If present, insertion should be delayed pending further diagnostic testing. These patients remain candidates for IUD placement in the future, but placement should be delayed until 3 months after the treatment of PID. ${ }^{2}$

Along with the exaggerated concern of PID among IUD users comes the concern of infertility associated with IUD use.

Table 2 Contraindications to IUD use

- Current pregnancy

- Purulent cervicitis

- Current pelvic inflammatory disease

- Immediate postseptic abortion

- Puerperal sepsis

- Current gestational trophoblastic disease

- Current cervical cancer

- Untreated endometrial cancer

- Unexplained vaginal bleeding

- Distorted uterine cavity

- Pelvic tuberculosis

Note: Data from US Medical Eligibility Criteria for Contraceptive Use, 2010. Centers for Disease Control and Prevention (CDC). MMWR Recomm Rep. 2010;59 (RR-4): I-86. ${ }^{31}$

Abbreviation: IUD, intrauterine device.
Worries over infertility are a barrier to IUD use in adolescents when medical providers have been surveyed..$^{32}$ Reassurance regarding the protection of fertility comes from a landmark study conducted in 2001. This case control study of nulliparous women seeking treatment for primary infertility showed no association between tubal infertility and past IUD use. ${ }^{33}$ Furthermore, pregnancy rates at 1 year following IUD removal in women under age 30 are equivalent to pregnancy rates in women not using any form of birth control. ${ }^{34}$

Uterine perforation is a rare complication with IUD insertion. This involves the placement of the IUD through the wall of the uterus, into the peritoneal cavity. The estimated occurrence is $0-1.3$ per 1,000 insertions, and surgical removal is recommended if this occurs. ${ }^{35,36}$ This removal procedure is not an emergency in an asymptomatic patient. The use of another IUD in the future is also not precluded in these patients, though allowing the uterus to heal for 4-6 weeks prior to placement of another IUD is recommended. ${ }^{6}$ Embedment within the myometrium is also a rare complication. In a study of 75 uterine perforations between 1996-2009, only $9 \%$ had difficult removal by pulling on visible strings, suggesting embedment within the myometrium. ${ }^{37}$ Failure to visualize strings at the cervical os or difficulty with removal should prompt the clinician to assess for uterine perforation or embedment.

Expulsion of IUDs, while still rare, is the most common complication following IUD insertion, and patients should be 
counseled regarding this possibility prior to placement. ${ }^{38}$ The available data regarding the LNG-20 IUD and copper IUD report similar expulsions rates for nulliparous and parous women of approximately 5\%. ${ }^{39,40}$ In the LNG-14 IUD clinical trial, the 3-year cumulative expulsion rate was $4.56 \% .{ }^{15}$ Prior expulsion does not preclude placement of another IUD provided that appropriate counseling is given. ${ }^{9}$

An additional perceived risk with IUD use is that of ectopic pregnancy. This risk is a myth that has been perpetuated, as in fact the use of IUDs decreases the risk of ectopic pregnancy just as IUDs decrease the risk of pregnancy overall. ${ }^{2}$ The risk of ectopic pregnancy is $0-0.5$ per 1,000 women-years among women using IUDs, compared to a rate of 3.25-5.25 per 1,000 women-years among women who do not use contraception. ${ }^{41,42}$ If a patient does become pregnant with an IUD in place, the proportion of an ectopic pregnancy is higher, although the absolute risk remains low. This is a distinction that needs to be clear during preprocedure counseling. The CDC classifies the use of both the LNG IUD and copper IUD in women with a history of ectopic as a Category 1; no restriction to use (Table 1). ${ }^{31}$

Safety after abortion and placement postpartum has been well studied. The CDC classifies placement of either IUD postabortion or postpartum as either Category 1 or $2 .{ }^{31}$ Immediate placement after delivery or a second trimester abortion are classified as Category 2 due to the increased risk of expulsion; however, the benefits outweigh the risks. ${ }^{31}$ If delayed insertion presents a significant barrier to patient care, then immediate or early insertion should be considered. This is especially prudent in adolescent populations, where up to $20 \%$ of adolescent mothers give birth again within 2 years. ${ }^{43}$ It has also been demonstrated that insertion of an IUD immediately after abortion significantly reduces the risk of repeat abortion. ${ }^{44}$ The exception to postabortion and postpartum insertion is in the event of puerperal sepsis or septic abortions, which are both contraindications to IUD placement (Table 2). In both scenarios, placement of IUDs can be performed 3 months following treatment of the infection. ${ }^{2}$

\section{Noncontraceptive benefits of IUDs}

While efficacy in pregnancy prevention makes IUDs a standout among contraceptive choices, the noncontraceptive benefits that come along with IUD use strengthen their marketability, appeal, and use for women seeking less invasive treatment for calamities such as pelvic pain, menorrhagia, endometriosis, and protection from endometrial hyperplasia. As the mechanism of action remains localized to the uterus
Table 3 Noncontraceptive benefits of IUDs

- Treatment of menorrhagia

- Improved anemia

- Improved dysmenorrhea

- Treatment of pelvic pain associated with endometriosis

- Endometrial protection during hormone replacement

- Endometrial protection against hyperplasia in patients at risk

- Use in women with medical comorbidities and contraindications to other systemic contraceptives

Abbreviation: IUD, intrauterine device.

and cervix, with little if any systemic effect, IUDs are an optimal method for women with multiple medications or medical comorbidities. Common medical conditions for which IUD use is accepted as safe based on CDC guidelines are listed in Table 1. Noncontraceptive benefits are summarized in Table 3.

The most highly recognized noncontraceptive benefit is with the use of the LNG-20 IUD to decrease menstrual blood loss. In 2009 the LNG-20 IUD received FDA approval for the treatment of heavy menstrual bleeding. In a review of five studies using the LNG-20 IUD, reductions in measured menstrual blood loss varied from $74 \%-97 \%$ at 12 months of use. ${ }^{45-49}$ Another case series demonstrated decreased menstrual blood loss by $95 \%$ at 6 months of use. ${ }^{50}$ In studies measuring hemoglobin change among women using the LNG-20 IUD, gain in hemoglobin concentration varied with duration of follow-up, yet all showed a net increase in concentration compared to measurements prior to IUD insertion. Increases in hemoglobin concentration are not found with the copper IUD. ${ }^{51-53}$ Due to this health benefit, the LNG-20 IUD should be considered over hysterectomy in women with heavy menstrual bleeding without structural anomalies. ${ }^{54}$ The use of the LNG-20 IUD is less invasive than surgical procedures, posing less risks to patients, and is more cost effective when compared to hysterectomy and endometrial ablation..$^{55,56}$

There are no dedicated studies to the use of the LNG-20 IUD for the treatment of menorrhagia in adolescent patients, yet the effects on decreased menstrual blood loss can be extrapolated to this population. ${ }^{57}$ One study that randomized women aged 18-25 years to either the LNG-20 IUD or oral contraceptive pills found significantly higher rates of decreased bleeding in the LNG-20 IUD group. ${ }^{25}$ A case series of adolescents with bleeding disorders also demonstrated effectiveness of this method to decrease menstrual blood loss in unique populations. ${ }^{58}$ There are several published studies regarding the use of the LNG-20 IUD in adults with bleeding disorders, resulting in a decrease in menstrual blood loss between $68 \%-100 \% .{ }^{59-61}$ 
The newer LNG-14 IUD can also decrease menstrual blood loss, possibly not to the extent of the LNG-20 IUD, although multiple comparative trials are lacking. In Phase II clinical trials comparing the two levonorgestrel IUD doses, both showed increasing rates of amenorrhea over time. ${ }^{15,62}$ Furthermore, women using the LNG-14 IUD reported 4 days or less of menstrual bleeding per 90-day reference period after 6 months of use. ${ }^{62}$

Dysmenorrhea, or pain with menses, can also be decreased with the use of the LNG-20 IUD. A recent longitudinal study evaluating 2,102 women found that dysmenorrhea severity was decreased in women using the LNG-20 IUD and oral contraceptive pills. Dysmenorrhea did not change in women using copper IUDs or nonhormonal methods of contraception. ${ }^{63}$ One would assume that the decrease in dysmenorrhea would also be seen to some extent with the use of the LNG-14 IUD, given that the mechanism of action is the same as the LNG-20 IUD. Further studies are needed to validate this use of the lower dose IUD.

The use of the LNG-20 IUD has also been studied in the treatment of endometriosis-associated pelvic pain. Pilot studies have shown improved control of chronic pelvic pain and dyspareunia in women with endometriosis, ${ }^{64,65}$ and in women with dysmenorrhea associated with rectovaginal endometriosis. ${ }^{66}$ Thirty percent of patients showed improvement in endometriosis staging on subsequent laparoscopy after treatment with LNG-20 IUD for 6 months, ${ }^{67}$ and pain and bleeding decreased after 36 months of follow-up. ${ }^{68}$

Recent studies have randomized women with endometriosis to either LNG-20 IUD or gonadotropin-releasing hormone agonists (GnRHa), ${ }^{69,70}$ or expectant management postoperatively. ${ }^{71}$ In one study randomizing women to either LNG-20 IUD or GnRHa, both treatments were found to be effective in controlling pelvic pain at 6 months, ${ }^{69}$ however, those randomized to LNG-20 IUD had a continuation rate of $59 \%$ at 36 months, and $82 \%$ of these women reported a lower pain score compared to the GnRHa group. ${ }^{72}$ A double-blind study comparing postoperative LNG-20 IUD to expectant management showed decreased dysmenorrhea in the LNG-20 IUD group, and longer time to pain recurrence in this group compared to expectant management. ${ }^{71} \mathrm{~A}$ recent Cochrane Review confirmed that while studies are limited, there is consistent evidence showing that postoperative LNG-20 IUD use reduces the recurrence of painful periods in women with endometriosis. ${ }^{73}$ There are no randomized trials in adolescents with endometriosis, but a retrospective study showed a decrease in pain and bleeding in adolescents using the LNG-20 IUD for treatment of endometriosis. ${ }^{74}$ This is promising, as endometriosis can be a cause in $25 \%-38 \%$ of adolescents with pelvic pain. ${ }^{75}$

The progestin effects on the endometrium serve to protect against endometrial hyperplasia. The LNG-20 IUD can be used in women using estrogen replacement therapy, and the protective effects are sustained over the 5-year lifetime of the LNG-20 IUD. ${ }^{6}$ Studies of this effect using the LNG-14 IUD have not been conducted. Many studies have shown a decreased risk of endometrial cancer in IUD users compared to nonusers, as confirmed by a meta-analysis. Among IUD users (copper and LNG-20 IUD) the pooled odds ratio of endometrial cancer was 0.54 ( $95 \%$ confidence interval [CI], 0.47-0.63). ${ }^{76}$ The LNG-20 IUD has also been shown to cause regression of endometrial hyperplasia. In a nonrandomized study using the LNG-20 IUD, or oral progestins, or observation, the LNG-20 IUD was the superior treatment for women with simple and atypical endometrial hyperplasia, and no cases progressed to cancer when followed up to 106 months. ${ }^{77}$ These findings have further been substantiated by a meta-analysis of 24 observational studies, showing better treatment response of endometrial hyperplasia among LNG-20 IUD users compared to oral progestins. ${ }^{78}$

Protection of the endometrium is important in the adolescent population as well. Approximately $50 \%$ of adolescents age 12-19 years are obese, ${ }^{79}$ and chronic anovulation from unopposed estrogen and polycystic ovarian syndrome are prevalent comorbidities. ${ }^{57}$ Menstrual regulation and endometrial protection are key to the treatment of anovulation in adolescents, and the LNG-20 IUD serves as optimal therapy in patients who may not be candidates for oral contraceptive pills. Comorbidities such as hypertension, risk of deep venous thrombosis, and malabsorption related to bariatric surgery can limit the use of oral contraceptive pills. ${ }^{57}$

Along with providing noncontraceptive benefits, all IUDs offer a mechanism of action that poses less interference with systemic illnesses and systemic medications. This includes women with diabetes, vascular disease, smokers, those with history of thrombosis, and those with limited mental capacity. ${ }^{6,57}$

\section{Patient perspectives}

With the evidence now laid regarding effectiveness for contraception, safety of use, and benefits to use, the final question that remains is, "What do patients think?" Patients must be satisfied with their contraceptive method and choose to continue it. Without patient satisfaction and acceptability, all of the other data is useless. 
The contraceptive CHOICE project addressed these issues. This recent study provided no-cost contraception to over 9,000 women ages 14-45 years in the city of St Louis, Missouri, USA and surrounding counties. The women received structured counseling regarding contraceptive options; when given the choice, $75 \%$ of them chose a LARC option, either IUD or implant. Furthermore, among women under 21 years participating, $69 \%$ chose a LARC option. ${ }^{16}$ This demonstrates that with appropriate counseling of risks and benefits, women will choose the options that are most effective to prevent pregnancy. In this same cohort, satisfaction rates and continuation rates with IUDs were higher than any other method. Among IUD users, the 12-month satisfaction rate for the LNG-20 IUD was $85.7 \%$, which mirrored the 12-month continuation rate of $87.5 \%$. The copper IUD continuation rate was $84 \%$ at 12 months, with $80 \%$ satisfied. Continuation of the implant, the other LARC method, was $83 \%$ at 12 months, with $79 \%$ satisfied. Continuation rates of either IUD type were far better than the continuation rates of nonlong-acting methods (pill, patch, ring, injection), which were $55 \%$ at 12 months. ${ }^{16,80}$ Among younger women under the age of 21 years, the LNG-20 IUD had the highest continuation rate of $85 \%$, and the copper IUD had a rate of $75.6 \%$ at 12 months, both higher than any nonlong-acting method. ${ }^{15,79}$

Other studies agree that IUD users report higher satisfaction than users of other methods. One US-based nationwide survey of women age 21-54 showed that overall, $99 \%$ of IUD users who continued the method beyond 12 months reported being "very satisfied" or "somewhat satisfied" with the method. ${ }^{81}$ A study involving postpartum adolescent females using depot medroxyprogesterone acetate (DMPA) injection and the LNG-20 IUD for contraception showed that satisfaction rates did not differ between methods at 6 and 12 months, but the intention to continue the LNG-20 IUD was higher than DMPA. A greater proportion of DMPA users found that the unpredictability and quantity of their bleeding was unacceptable compared with LNG-20 IUD users.$^{82}$ Another study reviewed satisfaction rates among IUD and implant users age 18 and over, along with reasons for early removal. The LNG-20 IUD had a $74 \%$ satisfaction rate, compared to $70 \%$ satisfaction with the implant. Of women who had early removal of their IUD, $68 \%$ reported pain, $63 \%$ reported irregular menses, and $40 \%$ reported increased frequency of menstrual bleeding. Nulliparous women were less likely to have early removal compared to multiparous women in this study. ${ }^{83}$

The most frequently reported reasons for liking IUDs are ease of use, reliability, and for the LNG IUD, lighter menstrual cycles. ${ }^{6}$ Abnormal bleeding and cramping are the most common reasons for discontinuation of both copper and LNG IUDs. The effect of LNG on the endometrium causes decidualization and thinning over time. This sequence accounts for the initial irregular bleeding pattern that is seen in most users, that improves over time. ${ }^{6}$ With the newer LNG-14 IUD, clinical trials demonstrated a discontinuation rate of $4.7 \%$ over 3 years due to irregular bleeding patterns, including amenorrhea. ${ }^{15}$ It is imperative then that patients are counseled appropriately regarding expected bleeding patterns with IUD use. Patients must understand that with the LNG IUDs, bleeding may be irregular, but that overall menstrual blood loss will decrease over time. Pelvic pain and cramping must also be addressed as a side effect of any IUD. A study reviewing IUD discontinuation prior to 6 months of use found a discontinuation rate of $7 \%$. Of these patients using the LNG-20 IUD and copper IUD, 27\% and 34\% stated pelvic pain as the reason for discontinuation, respectively. ${ }^{84}$

Patients must also be counseled regarding cramping after the procedure itself. This should be done prior to placement, and information with specific details should be given after insertion, such as in Table 4. Thorough counseling about expected changes in bleeding patterns before IUD insertion correlates with satisfaction rates and continuation rates. ${ }^{85}$

\section{Specific considerations}

Patient lack of knowledge about IUDs, practitioner counseling, and cost all continue to be barriers to IUD use. This is particularly poignant in their use among nulliparous adolescents and young women. Use of IUDs has increased among sexually experienced adolescents (age 15-19 years) and young women (age 20-24 years) from 2002 to 2010, but still remains under 5\%. The use among nulliparous women remains even lower, under $1 \%{ }^{86}$ This likely reflects the previously discussed misconceptions and restrictions concerning adolescents and nulliparous women. Despite growing evidence and statements from governing bodies such as the American College of Obstetrician and Gynecologists supporting the use of IUDs in these populations, many of these beliefs and barriers still persist.

In some populations, $50 \%$ of adolescents have never heard of an IUD. ${ }^{87}$ Furthermore, counseling from the practitioners that they come in contact with may provide poor or inaccurate information. Approximately one-third to one-half of providers (obstetricians/gynecologists, family medicine physicians, physician assistants, and nurses) believe that IUDs are not appropriate for nulliparous women, and nearly two-thirds do not believe they are appropriate for adolescents. ${ }^{88}$ Pediatricians 
Table 4 Post-IUD instructions for patients

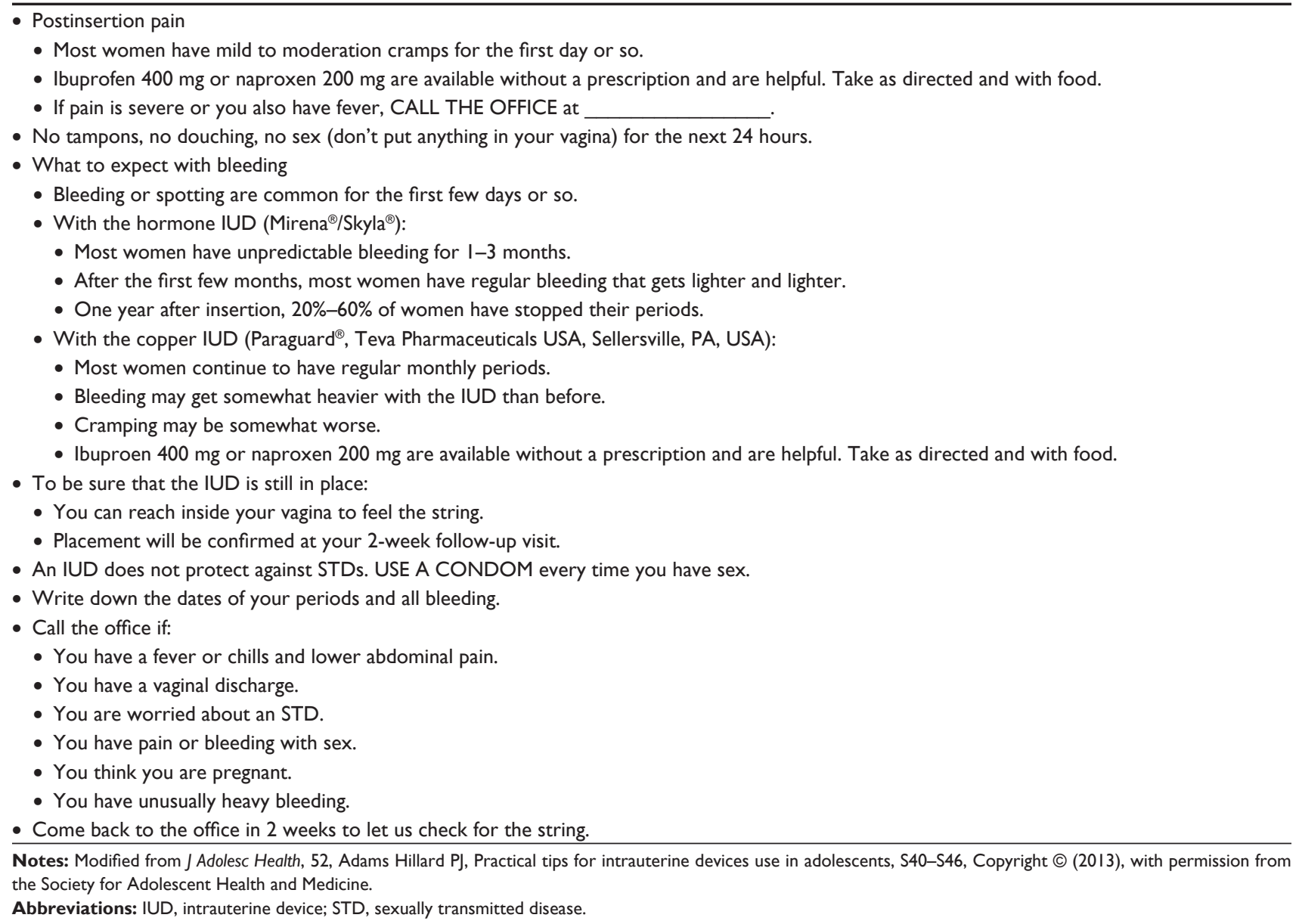

are a mainstay in adolescent contraceptive counseling, yet can also be a barrier to IUD use in this population. In one study, $98 \%$ of pediatricians surveyed reported that they addressed contraception with their adolescent patients, yet only $19 \%$ included discussion of IUDs, and only $10 \%$ would recommend an IUD to an adolescent patient. Furthermore, less than $25 \%$ recommended that an adolescent should be offered an IUD if she had ever had an STD, had multiple sexual partners, was nulligravid, or was not yet sexually active. ${ }^{32}$ Time constraints and concerns of parental reaction are often cited as barriers to IUD discussion with adolescents. ${ }^{32}$ Both are legitimate concerns, and a study of parental acceptability of contraceptive options found that only $18 \%$ of those parents surveyed viewed the IUD as an acceptable option for adolescents. ${ }^{89}$ It is possible that parents view short-acting methods as associated with single sexual episodes, whereas longer-acting methods suggest an ongoing sexual relationship.

The high up-front cost of IUDs is another important barrier to use for women of any age. The average wholesale price of the LNG-20 IUD is $\$ 844$, and the copper IUD is
\$718. These figures do not include the office visit cost and procedure cost. ${ }^{90}$ Provision of no-cost contraception has shown to decrease unintended birth rate, abortions, and repeat abortions. ${ }^{91}$ In a study among women seeking abortion services, 24\% reported the cost of contraception as the reason they did not use a method to prevent pregnancy. ${ }^{92}$ Another study demonstrated that among women with employersponsored health insurance, rates of IUD initiation were higher when cost-sharing was lower, even after accounting for cost-sharing levels of other contraceptive methods. ${ }^{93}$ These studies are concordant showing that when cost is removed, women are more likely to use long-acting options such as IUDs for contraception. Contraceptive coverage laws continue to change and be debated. As this process evolves, we continue to take note of the efficacy found by programs that provide no-cost contraception.

\section{Conclusion}

Despite clear guidelines based on good evidence, adolescents, parents, and clinicians continue to express concerns 
about IUDs. Some concerns are based on poor evidence or misconceptions; some may be based on truth, and simply require additional counseling or information. Myths affect uptake of these methods among populations that may need this information and access the most.

IUDs are safe and effective in women of any reproductive age. They offer superior contraceptive efficacy, plus noncontraceptive benefits that can improve quality of life in many women. Clear and accurate counseling needs to be provided to patients when choosing a contraceptive method, or when using the IUD for medical indications. The dispersion of accurate information is imperative to the continued use and growing acceptance of this beneficial method.

\section{Disclosure}

The author reports no conflicts of interest in this work.

\section{References}

1. Mosher WD, Jones J. Use of contraception in the United States: 1982-2008. Vital Health Stat 23. 2010(29):1-44.

2. American College of Obstetricians and Gynecologists. ACOG Practice Bulletin No. 121: Long-acting reversible contraception: Implants and intrauterine devices. Obstet Gynecol. 2011;118(1):184-196.

3. Rivera R, Yacobson I, Grimes D. The mechanism of action of hormonal contraceptives and intrauterine contraceptive devices. Am J Obstet Gynecol. 1999;181(5 Pt 1):1263-1269.

4. Stanford JB, Mikolajczyk RT. Mechanisms of action of intrauterine devices: update and estimation of postfertilization effects. Am J Obstet Gynecol. 2002;187(6):1699-1708.

5. Hubacher D, Grimes DA. Noncontraceptive health benefits of intrauterine devices: a systematic review. Obstet Gynecol Surv. 2002;57(2): 120-128.

6. Bednarek PH, Jensen JT. Safety, efficacy and patient acceptability of the contraceptive and non-contraceptive uses of the LNG-IUS. Int $J$ Womens Health. 2010;1:45-58.

7. Nilsson CG, Lähteenmäki PL, Luukkainen T. Ovarian function in amenorrheic and menstruating users of a levonorgestrel-releasing intrauterine device. Fertil Steril. 1984;41(1):52-55.

8. Hubacher D, Reyes V, Lillo S, Zepeda A, Chen PL, Croxatto H. Pain from copper intrauterine device insertion: randomized trial of prophylactic ibuprofen. Am J Obstet Gynecol. 2006;195(5):1272-1277.

9. ACOG Committee Opinion No. 392, December 2007. Intrauterine device and adolescents. Obstet Gynecol. 2007;110(6):1493-1495.

10. Allen RH, Bartz D, Grimes DA, Hubacher D, O'Brien P. Interventions for pain with intrauterine device insertion. Cochrane Database Syst Rev. 2009CD007373.

11. Hamilton BE, Ventura SJ. Birth rates for US teenagers reach historic lows for all age and ethnic groups. NCHS Data Brief. 2012;(89):1-8.

12. Hatcher RA, Trussell J, Nelson AL, Cates W Jr, Stewart FH, Kowal D, editors. Contraceptive Technology. 19th rev. ed. New York (NY) Ardent Media; 2007.

13. French R, Van Vliet H, Cowan F, et al. Hormonally impregnated intrauterine systems (IUSs) versus other forms of reversible contraceptives as effective methods of preventing pregnancy. Cochrane Database Syst Rev. 2004CD001776.

14. Trussell J. Contraceptive failure in the United States. Contraception. 2011;83(5):397-404.

15. Nelson A, Apter D, Hauck B, et al. Two low-dose levonorgestrel intrauterine contraceptive systems: a randomized controlled trial. Obstet Gynecol. 2013;122(6):1205-1213.
16. Winner B, Peipert JF, Zhao Q, et al. Effectiveness of long-acting reversible contraception. N Engl J Med. 2012;366(21):1998-2007.

17. Raine TR, Foster-Rosales A, Upadhyay UD, et al. One-year contraceptive continuation and pregnancy in adolescent girls and women initiating hormonal contraceptives. Obstet Gynecol. 2011;117(2 Pt 1): 363-371.

18. Centers for Disease Control and Prevention (CDC). Sexual experience and contraceptive use among female teens - United States, 1995, 2002, and 2006-2010. MMWR. Morb Mortal Wkly Rep. 2012;61(17): 297-301.

19. Swanson KJ, Gossett DR, Fournier M. Pediatricians' beliefs and prescribing patterns of adolescent contraception: a provider survey. J Pediatr Adolesc Gynecol. 2013;26(6):340-345.

20. Tyler CP, Whiteman MK, Zapata LB, Curtis KM, Hillis SD, Marchbanks PA. Health care provider attitudes and practices related to intrauterine devices for nulliparous women. Obstet Gynecol. 2012;119(4):762-771.

21. Farley TM, Rosenberg MJ, Rowe PJ, Chen JH, Meirik O. Intrauterine devices and pelvic inflammatory disease: an international perspective. Lancet. 1992;339(8796):785-788.

22. Simms I, Rogers P, Charlett A. The rate of diagnosis and demography of pelvic inflammatory disease in general practice: England and Wales. Int J STD AIDS. 1999;10(7):448-451.

23. Weström L. Incidence, prevalence, and trends of acute pelvic inflammatory disease and its consequences in industrialized countries. $\mathrm{Am} \mathrm{J}$ Obstet Gynecol. 1980;138(7 Pt 2):880-892.

24. Grimes DA. Intrauterine device and upper-genital-tract infection. Lancet. 2000;356(9234):1013-1019.

25. Suhonen S, Haukkamaa M, Jakobsson T, Rauramo I. Clinical performance of a levonorgestrel-releasing intrauterine system and oral contraceptives in young nulliparous women: a comparative study. Contraception. 2004;69(5):407-412.

26. Sutton MY, Sternberg M, Zaidi A, St Louis ME, Markowitz LE. Trends in pelvic inflammatory disease hospital discharges and ambulatory visits, United States, 1985-2001. Sex Transm Dis. 2005;32(12):778-784.

27. Weinstock H, Berman S, Cates W. Sexually transmitted diseases among American youth: incidence and prevalence estimates, 2000. Perspect Sex Reprod Health. 2004;36(1):6-10.

28. Carr S, Espey E. Intrauterine devices and pelvic inflammatory disease among adolescents. $J$ Adolesc Health. 2013;52(4 Suppl):S22-S28.

29. Mohllajee AP, Curtis KM, Peterson HB. Does insertion and use of an intrauterine device increase the risk of pelvic inflammatory disease among women with sexually transmitted infection? A systematic review. Contraception. 2006;73(2):145-153.

30. Faúndes A, Telles E, Cristofoletti ML, Faúndes D, Castro S, Hardy E. The risk of inadvertent intrauterine device insertion in women carriers of endocervical Chlamydia trachomatis. Contraception. 1998;58(2): 105-109.

31. Centers for Disease Control and Prevention (CDC). US Medical Eligibility Criteria for Contraceptive Use, 2010. MMWR Recomm Rep. 2010;59(RR-4):1-86.

32. Wilson SF, Strohsnitter W, Baecher-Lind L. Practices and perceptions among pediatricians regarding adolescent contraception with emphasis on intrauterine contraception. $J$ Pediatr Adolesc Gynecol. 2013;26(5):281-284.

33. Hubacher D, Lara-Ricalde R, Taylor DJ, Guerra-Infante F, GuzmánRodríguez R. Use of copper intrauterine devices and the risk of tubal infertility among nulligravid women. N Engl J Med. 2001;345(8):561-567.

34. Andersson K, Batar I, Rybo G. Return to fertility after removal of a levonorgestrel-releasing intrauterine device and Nova-T. Contraception. 1992;46(6):575-584.

35. Andersson K, Ryde-Blomqvist E, Lindell K, Odlind V, Milsom I. Perforations with intrauterine devices. Report from a Swedish survey. Contraception. 1998;57(4):251-255.

36. Mechanism of action, safety and efficacy of intrauterine devices. Report of a WHO Scientific Group. World Health Organ Tech Rep Ser. 1987;753:1-91. 
37. Kaislasuo J, Suhonen S, Gissler M, Lähteenmäki P, Heikinheimo O. Uterine perforation caused by intrauterine devices: clinical course and treatment. Hum Reprod. 2013;28(6):1546-1551.

38. Russo JA, Miller E, Gold MA. Myths and misconceptions about long-acting reversible contraception (LARC). J Adolesc Health. 2013;52(4 Suppl):S14-S21.

39. Hubacher D. Copper intrauterine device use by nulliparous women: review of side effects. Contraception. 2007;75(6 Suppl):S8-S11.

40. Brockmeyer A, Kishen M, Webb A. Experience of IUD/IUS insertions and clinical performance in nulliparous women - a pilot study. Eur $J$ Contracept Reprod Health Care. 2008;13(3):248-254.

41. Sivin I. Dose- and age-dependent ectopic pregnancy risks with intrauterine contraception. Obstet Gynecol. 1991;78(2):291-298.

42. Sivin I, Stern J. Health during prolonged use of levonorgestrel 20 micrograms/d and the copper TCu $380 \mathrm{Ag}$ intrauterine contraceptive devices: a multicenter study. International Committee for Contraception Research (ICCR). Fertil Steril. 1994;61(1):70-77.

43. Boardman LA, Allsworth J, Phipps MG, Lapane KL. Risk factors for unintended versus intended rapid repeat pregnancies among adolescents. J Adolesc Health. 2006;39(4):597.e1-597.e8.

44. Goodman S, Hendlish SK, Reeves MF, Foster-Rosales A. Impact of immediate postabortal insertion of intrauterine contraception on repeat abortion. Contraception. 2008;78(2):143-148.

45. Irvine GA, Campbell-Brown MB, Lumsden MA, Heikkilä A, Walker JJ, Cameron IT. Randomised comparative trial of the levonorgestrel intrauterine system and norethisterone for treatment of idiopathic menorrhagia. Br J Obstet Gynaecol. 1998;105(6):592-598.

46. Barrington JW, Bowen-Simpkins P. The levonorgestrel intrauterine system in the management of menorrhagia. Br J Obstet Gynaecol. 1997;104(5):614-616.

47. Crosignani PG, Vercellini P, Mosconi P, Oldani S, Cortesi I, De Giorgi O. Levonorgestrel-releasing intrauterine device versus hysteroscopic endometrial resection in the treatment of dysfunctional uterine bleeding. Obstet Gynecol. 1997;90(2):257-263.

48. Andersson JK, Rybo G. Levonorgestrel-releasing intrauterine device in the treatment of menorrhagia. Br J Obstet Gynaecol. 1990;97(8): 690-694.

49. Fedele L, Bianchi S, Raffaelli R, Portuese A, Dorta M. Treatment of adenomyosis-associated menorrhagia with a levonorgestrel-releasing intrauterine device. Fertil Steril. 1997;68(3):426-429.

50. Tang GW, Lo SS. Levonorgestrel intrauterine device in the treatment of menorrhagia in Chinese women: efficacy versus acceptability. Contraception. 1995;51(4):231-235.

51. Andersson K, Odlind V, Rybo G. Levonorgestrel-releasing and copperreleasing (Nova T) IUDs during five years of use: a randomized comparative trial. Contraception. 1994;49(1):56-72.

52. Sivin I, Stern J, Diaz J, et al. Two years of intrauterine contraception with levonorgestrel and with copper: a randomized comparison of the $\mathrm{TCu} 380 \mathrm{Ag}$ and levonorgestrel $20 \mathrm{mcg} /$ day devices. Contraception. 1987;35(3):245-255.

53. Rönnerdag M, Odlind V. Health effects of long-term use of the intrauterine levonorgestrel-releasing system. A follow-up study over 12 years of continuous use. Acta Obstet Gynecol Scand. 1999;78(8):716-721.

54. Dueholm M. Levonorgestrel-IUD should be offered before hysterectomy for abnormal uterine bleeding without uterine structural abnormalities: there are no more excuses! Acta Obstet Gynecol Scand. 2009;88(12):1302-1304.

55. Marjoribanks J, Lethaby A, Farquhar C. Surgery versus medical therapy for heavy menstrual bleeding. Cochrane Database Syst Rev. 2006;(2):CD003855.

56. Hurskainen R, Teperi J, Rissanen P, et al. Quality of life and costeffectiveness of levonorgestrel-releasing intrauterine system versus hysterectomy for treatment of menorrhagia: a randomised trial. Lancet. 2001;357(9252):273-277.

57. Bayer LL, Hillard PJ. Use of levonorgestrel intrauterine system for medical indications in adolescents. J Adolesc Health. 2013;52(4 Suppl): S54-S58.
58. Chi C, Pollard D, Tuddenham EG, Kadir RA. Menorrhagia in adolescents with inherited bleeding disorders. $J$ Pediatr Adolesc Gynecol. 2010;23(4):215-222.

59. Chi C, Huq FY, Kadir RA. Levonorgestrel-releasing intrauterine system for the management of heavy menstrual bleeding in women with inherited bleeding disorders: long-term follow-up. Contraception. 2011;83(3):242-247.

60. Schaedel ZE, Dolan G, Powell MC. The use of the levonorgestrelreleasing intrauterine system in the management of menorrhagia in women with hemostatic disorders. Am J Obstet Gynecol. 2005;193(4): 1361-1363.

61. Lukes AS, Reardon B, Arepally G. Use of the levonorgestrel-releasing intrauterine system in women with hemostatic disorders. Fertil Steril. 2008;90(3):673-677.

62. Gemzell-Danielsson K, Schellschmidt I, Apter D. A randomized, phase II study describing the efficacy, bleeding profile, and safety of two low-dose levonorgestrel-releasing intrauterine contraceptive systems and Mirena. Fertil Steril. 2012;97(3):616-22.e1.

63. Lindh I, Milsom I. The influence of intrauterine contraception on the prevalence and severity of dysmenorrhea: a longitudinal population study. Hum Reprod. 2013;28(7):1953-1960.

64. Vercellini P, Aimi G, Panazza S, De Giorgi O, Pesole A, Crosignani PG. A levonorgestrel-releasing intrauterine system for the treatment of dysmenorrhea associated with endometriosis: a pilot study. Fertil Steril. 1999;72(3):505-508.

65. Vercellini P, Frontino G, De Giorgi O, Aimi G, Zaina B, Crosignani PG. Comparison of a levonorgestrel-releasing intrauterine device versus expectant management after conservative surgery for symptomatic endometriosis: a pilot study. Fertil Steril. 2003;80(2):305-309.

66. Fedele L, Bianchi S, Zanconato G, Portuese A, Raffaelli R. Use of a levonorgestrel-releasing intrauterine device in the treatment of rectovaginal endometriosis. Fertil Steril. 2001;75(3):485-488

67. Lockhat FB, Emembolu JO, Konje JC. The evaluation of the effectiveness of an intrauterine-administered progestogen (levonorgestrel) in the symptomatic treatment of endometriosis and in the staging of the disease. Hum Reprod. 2004;19(1):179-184

68. Lockhat FB, Emembolu JO, Konje JC. The efficacy, side-effects and continuation rates in women with symptomatic endometriosis undergoing treatment with an intra-uterine administered progestogen (levonorgestrel): a 3 year follow-up. Hum Reprod. 2005;20(3):789-793.

69. Petta CA, Ferriani RA, Abrao MS, et al. Randomized clinical trial of a levonorgestrel-releasing intrauterine system and a depot $\mathrm{GnRH}$ analogue for the treatment of chronic pelvic pain in women with endometriosis. Hum Reprod. 2005;20(7):1993-1998.

70. Bayoglu Tekin Y, Dilbaz B, Altinbas SK, Dilbaz S. Postoperative medical treatment of chronic pelvic pain related to severe endometriosis: levonorgestrel-releasing intrauterine system versus gonadotropin-releasing hormone analogue. Fertil Steril. 2011;95(2): 492-496.

71. Tanmahasamut P, Rattanachaiyanont M, Angsuwathana S, Techatraisak K, Indhavivadhana S, Leerasiri P. Postoperative levonorgestrel-releasing intrauterine system for pelvic endometriosisrelated pain: a randomized controlled trial. Obstet Gynecol. 2012; 119(3):519-526.

72. Petta CA, Ferriani RA, Abrão MS, et al. A 3-year follow-up of women with endometriosis and pelvic pain users of the levonorgestrelreleasing intrauterine system. Eur J Obstet Gynecol Reprod Biol. 2009;143(2):128-129.

73. Abou-Setta AM, Houston B, Al-Inany HG, Farquhar C. Levonorgestrelreleasing intrauterine device (LNG-IUD) for symptomatic endometriosis following surgery. Cochrane Database Syst Rev. 2013;1:CD005072.

74. Yoost J, LaJoie AS, Hertweck P, Loveless M. Use of the levonorgestrel intrauterine system in adolescents with endometriosis. J Pediatr Adolesc Gynecol. 2013;26(2):120-124.

75. American College of Obstetricians and Gynecologists. ACOG Committee Opinion. Number 310, April 2005. Endometriosis in adolescents. Obstet Gynecol. 2005;105(4):921-927. 
76. Beining RM, Dennis LK, Smith EM, Dokras A. Meta-analysis of intrauterine device use and risk of endometrial cancer. Ann Epidemiol. 2008;18(6):492-499.

77. Ørbo A, Arnes M, Hancke C, Vereide AB, Pettersen I, Larsen K. Treatment results of endometrial hyperplasia after prospective D-score classification: a follow-up study comparing effect of LNGIUD and oral progestins versus observation only. Gynecol Oncol. 2008;111(1):68-73.

78. Gallos ID, Shehmar M, Thangaratinam S, Papapostolou TK, Coomarasamy A, Gupta JK. Oral progestogens vs levonorgestrelreleasing intrauterine system for endometrial hyperplasia: a systematic review and meta-analysis. Am J Obstet Gynecol. 2010;203(6):547. e1-547.e10.

79. Ogden CL, Carroll MD, Kit BK, Flegal KM. Prevalence of obesity and trends in body mass index among US children and adolescents, 1999-2010. JAMA. 2012;307(5):483-490.

80. Peipert JF, Zhao Q, Allsworth JE, et al. Continuation and satisfaction of reversible contraception. Obstet Gynecol. 2011;117(5):1105-1113.

81. Forrest JD. US women's perceptions of and attitudes about the IUD. Obstet Gynecol Surv. 1996;51(12 Supp1):S30-S34.

82. Howard DL, Wayman R, Strickland JL. Satisfaction with and intention to continue Depo-Provera versus the Mirena IUD among post-partum adolescents through 12 months of follow-up. JPediatr Adolesc Gynecol. 2013;26(6):358-365.

83. Dickerson LM, Diaz VA, Jordon J, et al. Satisfaction, early removal, and side effects associated with long-acting reversible contraception. Fam Med. 2013;45(10):701-707.

84. Grunloh DS, Casner T, Secura GM, Peipert JF, Madden T. Characteristics associated with discontinuation of long-acting reversible contraception within the first 6 months of use. Obstet Gynecol. 2013;122(6): 1214-1221.
85. Hillard PJ. Practical tips for intrauterine devices use in adolescents. $J$ Adolesc Health. 2013;52(4 Suppl):S40-S46.

86. Whitaker AK, Sisco KM, Tomlinson AN, Dude AM, Martins SL. Use of the intrauterine device among adolescent and young adult women in the United States from 2002 to 2010. J Adolesc Health. 2013;53(3):401-406.

87. Stanwood NL, Bradley KA. Young pregnant women's knowledge of modern intrauterine devices. Obstet Gynecol. 2006;108(6):1417-1422.

88. Kavanaugh ML, Frohwirth L, Jerman J, Popkin R, Ethier K. Long-acting reversible contraception for adolescents and young adults: patient and provider perspectives. J Pediatr Adolesc Gynecol. 2013;26(2):86-95.

89. Hartman LB, Shafer MA, Pollack LM, Wibbelsman C, Chang F, Tebb KP. Parental acceptability of contraceptive methods offered to their teen during a confidential health care visit. J Adolesc Health. 2013; 52(2):251-254.

90. Eisenberg D, McNicholas C, Peipert JF. Cost as a barrier to long-acting reversible contraceptive (LARC) use in adolescents. J Adolesc Health. 2013;52(4 Supp1):S59-S63.

91. Peipert JF, Madden T, Allsworth JE, Secura GM. Preventing unintended pregnancies by providing no-cost contraception. Obstet Gynecol. 2012;120(6):1291-1297.

92. Homco JB, Peipert JF, Secura GM, Lewis VA, Allsworth JE. Reasons for ineffective pre-pregnancy contraception use in patients seeking abortion services. Contraception. 2009;80(6):569-574.

93. Pace LE, Dusetzina SB, Fendrick AM, Keating NL, Dalton VK. The impact of out-of-pocket costs on the use of intrauterine contraception among women with employer-sponsored insurance. Med Care. 2013;51(11):959-963.
Patient Preference and Adherence

\section{Publish your work in this journal}

Patient Preference and Adherence is an international, peer-reviewed, open access journal that focusing on the growing importance of patient preference and adherence throughout the therapeutic continuum. Patient satisfaction, acceptability, quality of life, compliance, persistence and their role in developing new therapeutic modalities and compounds to optimize

\section{Dovepress}

clinical outcomes for existing disease states are major areas of interest for the journal. This journal has been accepted for indexing on PubMed Central. The manuscript management system is completely online and includes a very quick and fair peer-review system, which is all easy to use. Visit http://www. dovepress.com/testimonials.php to read real quotes from published authors. 